\title{
Field Inoculation of Arbuscular Mycorrhizal Fungi Improves Fruit Quality and Root Physiological Activity of Citrus
}

\author{
Ming-Ao Cao ${ }^{1,+}{ }^{\dagger}$ Peng Wang $\left.{ }^{2,+}{ }^{(}\right)$, Abeer Hashem ${ }^{3}$, Stephan Wirth ${ }^{4}\left(\mathbb{C}\right.$, Elsayed Fathi Abd_Allah ${ }^{5}(\mathbb{C}$ \\ and Qiang-Sheng $\mathrm{Wu}^{1, *(D)}$ \\ 1 College of Horticulture and Gardening, Yangtze University, Jingzhou 434025, China; \\ 202071717@yangtzeu.edu.cn \\ 2 Institute of Citrus Research, Zhejiang Academy of Agricultural Sciences, Taizhou 318026, China; \\ peter_wang81@163.com \\ 3 Botany and Microbiology Department, College of Science, King Saud University, P.O. Box 2460, \\ Riyadh 11451, Saudi Arabia; habeer@ksu.edu.sa \\ 4 Leibniz Centre for Agricultural Landscape Research (ZALF), 15374 Müncheberg, Germany; swirth@zalf.de \\ 5 Plant Production Department, College of Food and Agricultural Sciences, King Saud University, \\ P.O. Box 2460, Riyadh 11451, Saudi Arabia; eabdallah@ksu.edu.sa \\ * Correspondence: wuqiangsheng@yangtzeu.edu.cn \\ + Co-first author.
}

check for updates

Citation: Cao, M.-A.; Wang, P.; Hashem, A.; Wirth, S.; Abd_Allah, E.F.; Wu, Q.-S. Field Inoculation of Arbuscular Mycorrhizal Fungi Improves Fruit Quality and Root Physiological Activity of Citrus. Agriculture 2021, 11, 1297. https:// doi.org/10.3390/agriculture11121297

Academic Editors: Tibor Szili-Kovács, Tünde Takács and Cristina Abbate

Received: 16 November 2021

Accepted: 17 December 2021

Published: 20 December 2021

Publisher's Note: MDPI stays neutral with regard to jurisdictional claims in published maps and institutional affiliations.

Copyright: (c) 2021 by the authors. Licensee MDPI, Basel, Switzerland. This article is an open access article distributed under the terms and conditions of the Creative Commons Attribution (CC BY) license (https:/ / creativecommons.org/licenses/by/ $4.0 /)$.

\begin{abstract}
Soil arbuscular mycorrhizal (AM) fungi form a mutualistic symbiosis with plant roots and produce many benefits on host plants under potted conditions, while field inoculation of AM fungi on citrus (a woody plant) has been rarely reported. The present study aimed to analyze the changes in mycorrhizal growth, root vitality, and fruit quality of Citrus reticulata Blanco var. Ponkan mandarin cv. Jinshuigan grafted on Poncirus trifoliata L. after inoculation with a mix of AM fungi (Diversispora versiformis, Funneliformis mosseae, and Rhizophagus intraradices) and single F. mosseae. After the second year of AM fungal inoculations, root mycorrhizal colonization (\%), root vitality, hyphal length in soil, and easily extractable glomalin-related soil protein content were significantly increased, while difficult-to-extract glomalin-related soil protein content was decreased. Two mycorrhizal fungal inoculation treatments collectively improved fruit quality parameters such as polar diameter, equatorial diameter, the weight of single fruits, fruit peel, and sarcocarp, coloration value, and soluble solids content. Our study, therefore, suggested that field inoculation with AM fungi improved root physiological activities in terms of mycorrhizal growth and root vitality and thus improved fruit quality. The effect of mixed-AM treatment was more significant than that of $F$. mosseae alone.
\end{abstract}

Keywords: citrus; fruit; glomalin; mycorrhizal inoculation; nutrient acquisition

\section{Introduction}

Arbuscular mycorrhizal (AM) fungi are beneficial soil microorganisms widely existing in nature colonizing the roots of about $80 \%$ of land plants including cereals, vegetables, and fruit trees [1]. Arbuscular mycorrhiza is a mutual-reciprocal symbiosis between AM fungi and host plants [2], where the host plant provides photosynthates for the growth of AM fungi, and AM fungi expand the absorption area of roots through extraradical hyphae and deliver water and nutrients to the host plant [3,4]. AM hyphae also produce a water-insoluble protein (glomalin) in soil (defined as glomalin-related soil protein GRSP), generally associated with insoluble humus or mineral fractions and contributing to stabilize soil aggregates [5]. Moreover, GRSP is considered to contribute to pools of soil organic carbon and providing positive impacts on plant growth [6,7]. The benefits that such AM fungi bring to host plants provide new pathways for the improvement of plant growth as well as sustainable agriculture and environmental management [8].

Citrus is a widely grown fruit tree globally with rare and short root hairs, heavily dependent upon the AM symbiosis to promote nutrient acquisition $[9,10]$. Generally, the 
AM fungal colonization rate of citrus roots in the field is quite low, less than $20 \%$, due to poor soil texture, environmental factors, and genetic factors, which may be a limiting factor affecting the high yield and good fruit quality of citrus [11]. Earlier studies have demonstrated that AM fungi had a mitigating effect on potted plants under soil moisture deficit $[12,13]$ or under heavy metal pollution of soil [14,15]. Regvar et al. [16] applied AM fungi in several industrial crops in the field. They found that AM fungi could increase the carotenoid content of carrot and tomato fruits, but also increase the chlorophyll content of coriander leaves. Similarly, Laura et al. [17] found that AM fungi effectively increased iron $(\mathrm{Fe})$ and zinc $(\mathrm{Zn})$ content of wheat grains. Other studies showed that AM fungi inoculation increased the content of starch and soluble carbohydrates in the leaves and roots of palm [18]. Paskovic et al. [19] analyzed the field response of AM fungal inoculation to fruit quality of tomato. They found an increase in total nitrogen $(\mathrm{N})$, magnesium $(\mathrm{Mg})$, and hydrophilic phenol contents in fruit. However, the application of AM fungi to plants in the field and further evaluation of its benefits are limited, especially in citrus plants [20].

The present study aimed to analyze the effect of AM fungi on the fruit quality of citrus in the field, to provide data-supported evidence for the applicability of AM fungi inoculation in citriculture.

\section{Materials and Methods}

\subsection{Experimental Setup}

The three-year-old Citrus reticulata Blanco var. Ponkan mandarin cv. Jinshuigan grafted on Poncirus trifoliata L. Raf. was selected and grown in a citrus orchard located in Jingzhou $\left(30^{\circ} 21^{\prime} 27^{\prime \prime} \mathrm{N}, 112^{\circ} 3^{\prime} 5^{\prime \prime} \mathrm{E}\right)$, Hubei, China. The trees in the citrus orchard had an inter-planting spacing of $3 \times 4 \mathrm{~m}$. The soil in the orchard is classified as XanthiUdic-Ferralsol according to the FAO system, and characterized by contents of available $\mathrm{N} 70.10 \mathrm{mg} / \mathrm{kg}$, Bray-extractable P $40.47 \mathrm{mg} / \mathrm{kg}$, available K $271.12 \mathrm{mg} / \mathrm{kg}$, and organic carbon $9.88 \mathrm{~g} / \mathrm{kg}$. In March 2018, the inoculation of exogenous AM fungi was carried out. Two inoculations, including single Funneliformis mosseae and a mixture of Diversispora versiformis, F. mosseae, and Rhizophagus intraradices were carried out. These AM fungi were provided by the Bank of Glomeromycota in China (BGC; Beijing, China). Meanwhile, the F. mosseae strain (BGC XJ02A), D. versiformis strain (BGC BJ08), and R. intraradices strain (BGC HUN02B) were isolated from the rhizosphere of Allium flavidum Ledeb. in Kangsu (Xinjiang, China), Cynodon dactylon (L.) Pers. in Guiyang (Hunan, China), and Lycopersicon esculentum Miller in Beijing (China), respectively. The identified spores of AM fungi were propagated by Trifolium repens $\mathrm{L}$. in a trap culture under greenhouse conditions $\left(880 \mu \mathrm{mol} / \mathrm{m}^{2} / \mathrm{s}\right.$ photo flux density, $28{ }^{\circ} \mathrm{C} / 20{ }^{\circ} \mathrm{C}$ day $/$ night temperature, and $68 \%$ relative air humidity). Three months later, the plants were harvested. The shoots were removed, and the mycorrhizal inoculum provided spores ( 20 spores/g for $F$. mosseae and 26 spores/g for mixed AM fungi), AM fungi-colonized root segments ( $82 \%$ for $F$. mosseae and $90 \%$ for mixed AM fungi), and soil mycelium. These mycorrhizal inocula were stored at $4{ }^{\circ} \mathrm{C}$ for no more than six months prior to use.

Fifteen citrus trees with similar vigor growth (plant height: $168.8 \pm 5.6 \mathrm{~cm}$; trunk diameter: $18.9 \pm 0.6 \mathrm{~mm}$ ) were divided into three groups: non-AM fungal inoculation (non-AMF), F. mosseae inoculation (FM), and mixed AM fungal inoculation (mixed-AMF). Each fungal inoculation was applied to five trees. In the selected tree trunk of a horizontal distance of $40 \mathrm{~cm}$ in north-south direction and east-west direction, a trench with $40 \mathrm{~cm} \times 15 \mathrm{~cm} \times 30 \mathrm{~cm}$ was dug. A total of $600 \mathrm{~g}$ mycorrhizal inoculum was applied into the trenches adjacent to citrus roots. After the soil was backfilled, seeds ( 300 seeds per tree) of white clover were sown on top of the soil filling the trenches to further promote the AM fungal development. For non-AM fungal treatments, the same amount of autoclaved mycorrhizal inocula were applied as a control. No organic amendment was supplied at the time of AM fungal inoculation. After AM fungal inoculations, all the treated trees received consistent field management. 


\subsection{Determinations of Variables}

The fruit sampling was carried out during the second year (2019) of fruit ripening in November. The twenty-five fruits were collected from different directions on each tree and immediately returned to the laboratory. The horizontal and vertical diameters of the fruit were determined with a digital vernier caliper. The weight of individual fruits was measured by an electronic balance. The color value of the fruit was calculated by a colorimeter (CR-400, Konica Minolta Sensing Inc., Osaka, Japan). The solid soluble content of the fruit was monitored by a digital refractometer (PAL-1, ATAGO Co., Tokyo, Japan). Fruit peel and sarcocarp weight was measured on the same day using a digital electronic balance.

The surface soil $(0-5 \mathrm{~cm})$ was removed and fine roots with a diameter of $0.5-1.0 \mathrm{~mm}$ of the current year were sampled in 5-15 cm of soil depth, gently shaking off the soil attached to the root being considered as rhizospheric soils. The soil and root samples were enclosed in sealed bags and taken back to the laboratory. Parts of root samples were used to analyze mycorrhizal colonization, and other root samples were utilized to determine nutrient element content.

The root samples were cut into 1-cm-long root segments, and mycorrhiza in the root segments was stained according to the protocol described by [21]. Arbuscular mycorrhiza were observed under a biomicroscope (NE610, Ningbo Yongxin Optics Co., Ltd., Ningbo, China). The root mycorrhizal colonization rate was calculated as the percentage of the colonized root-segment length versus the total observed root-segment length. Mycorrhizal hyphal length in the soil was determined according to the method described by [22]. The root vitality was determined by triphenyltetrazole chloride staining method as described by [23]. Two fractions of glomalin-related soil protein, including easily-extractable glomalinrelated soil protein (EE-GRSP), and difficult-to-extract glomalin-related soil protein (DEGRSP), were extracted and assayed collectively according to the method of [24].

\subsection{Statistical Analysis}

The experimental data were analyzed using the one-factor analysis of variation by SAS software. The Duncan multiple range test was used to compare significant differences between treatments $(p<0.05$; Duncan test).

\section{Results}

\subsection{Changes in Degree of Root Mycorrhizal Colonization, Soil Hyphal Length, and Root Vitality}

In the roots of 5-15 cm soil depth, a large extent of root mycorrhizal colonization was observed in the inoculated and uninoculated citrus trees (Figure 1a-c). External AM fungal inoculation into the rhizosphere of Ponkan mandarin, to some extent, increased the degree of root mycorrhizal fungal colonization, along with the increase of $62.0 \%$ in the mixed-AMF treatment versus the non-AMF treatment (Figure 2a). On the other hand, both the FM treatment and the mixed-AMF treatment significantly increased hyphal length in soil by $60.6 \%$ and $109.2 \%$ (Figure $2 \mathrm{~b}$ ) and root vitality by $55.3 \%$ and $60.5 \%$ (Figure $2 \mathrm{c}$ ), respectively. 
(a)

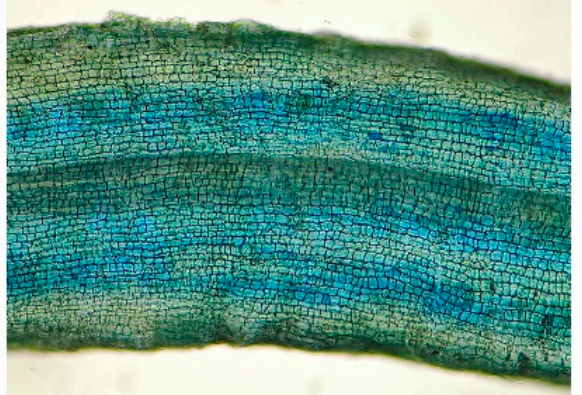

Non-AMF (b)

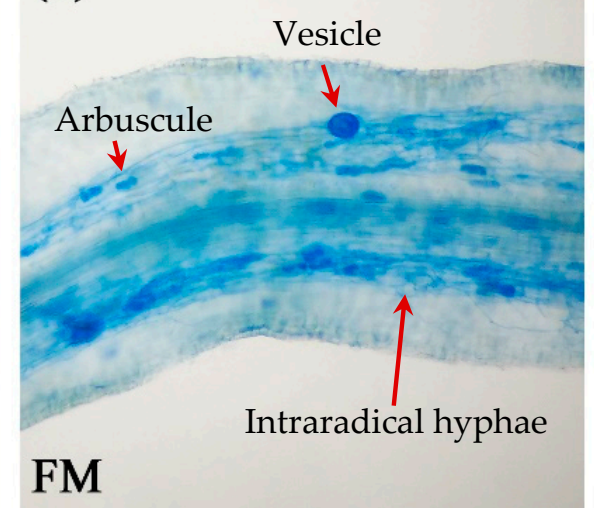

(c)

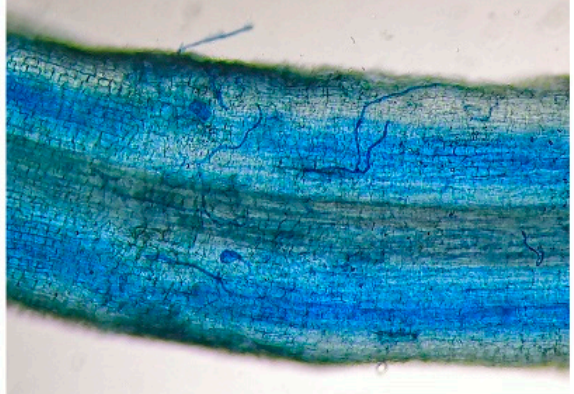

Mixed-AMF

Figure 1. Mycorrhizal colonization of Ponkan mandarin roots grafted on trifoliate orange under field inoculations with non-AMF (a), F. mosseae (b), and mixed-AMF (c), respectively. The fine roots of the current year were collected from 5-15 cm soil depth and stained with trypan blue in lactoglycerol. These figures of mycorrhizal colonization were taken and used to calculate the degree of root mycorrhizal fungal colonization.
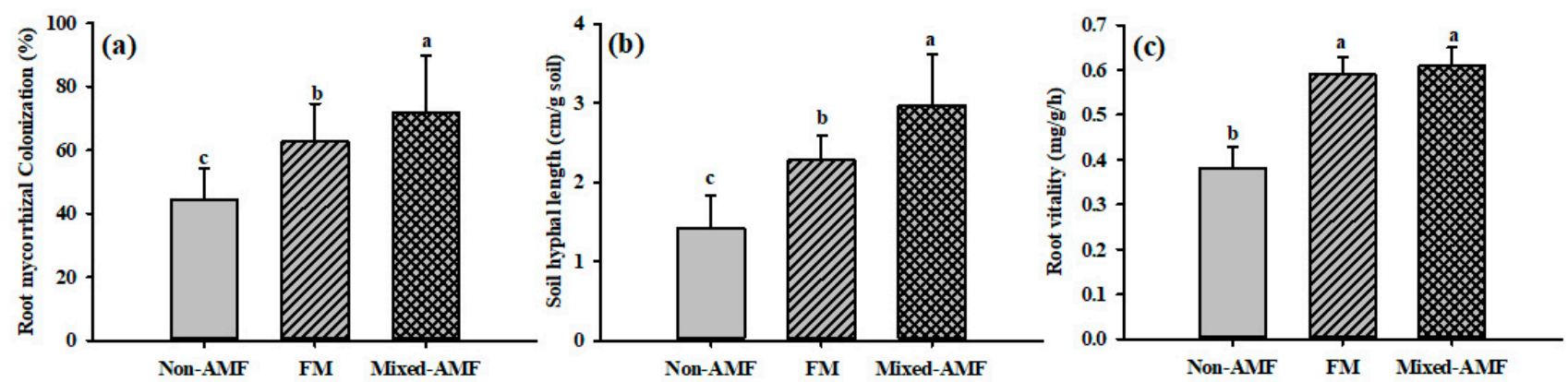

Figure 2. Effects of AMF inoculation on the degree of root mycorrhizal colonization (a), mycorrhizal hyphal length in soil (b), and root vitality (c) of Ponkan mandarin, grafted on trifoliate orange under field condition. Means \pm SD $(n=5)$ followed by different letters at the bar indicate significant differences $(p<0.05)$ among treatments. The data were collected in 2019, the second year after AMF inoculation.

\subsection{Changes in Soil GRSP Levels}

Compared with non-AMF treatment, the mixed-AMF and FM inoculations significantly increased easily extractable glomalin-related soil protein (EE-GRSP) concentrations by $41.1 \%$ and $40.3 \%$, respectively, while dramatically decreased difficult-to-extract glomalinrelated soil protein (DE-GRSP) concentrations by $27.5 \%$ and $37.2 \%$, respectively (Figure 3). There was no significant difference in EE-GRSP and DE-GRSP concentrations between mixed-AMF and FM treatments. 


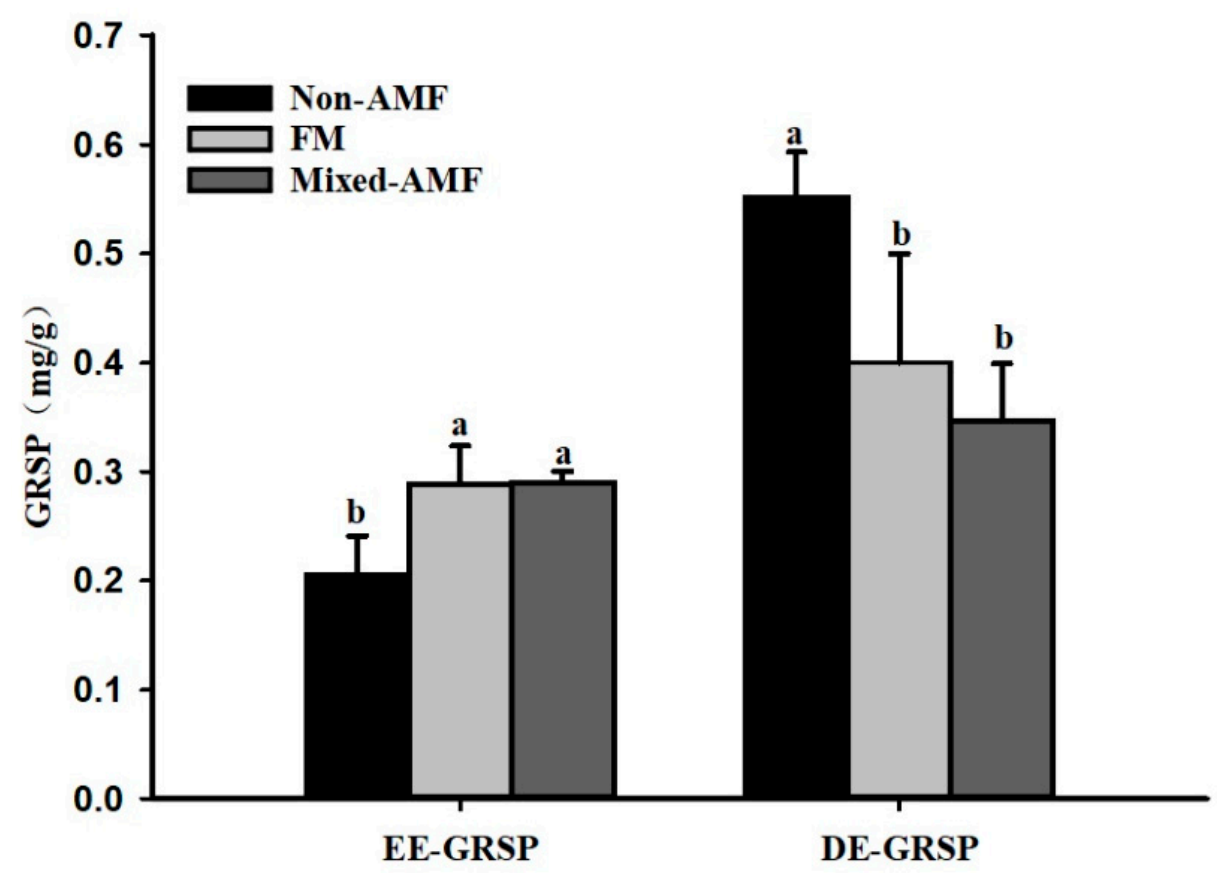

Figure 3. Effects of AMF inoculation on easily extractable glomalin-related soil protein (EE-GRSP) and difficult-to-extract glomalin-related soil protein (DE-GRSP) concentrations of Ponkan mandarin grafted on trifoliate orange under field conditions. Means $\pm \operatorname{SD}(n=5)$ followed by different letters at the bar indicate significant differences $(p<0.05)$ among treatments. The data were collected in 2019 , the second year after AMF inoculation.

\subsection{Changes in Internal and External Quality Parameters of Fruits}

In the second year after AM fungi inoculation, both mixed-AMF and FM treatments showed significant improvement in the internal and external quality of fruits in Ponkan mandarin (Table 1; Figure 4). Compared with the non-AMF treatment, single fruit weight, equatorial diameter, polar diameter, fruit peel weight, sarcocarp weight, total soluble solids content, and coloration value were significantly increased by $38.8,18.0,14.0,70.0,43.1$, 14.6 , and $4.7 \%$, respectively under mixed-AMF inoculation conditions, and by $32.2,13.0$, 14.2, 56.1, 36.7, 9.1, and 2.8\% under FM inoculation conditions, respectively. Moreover, mixed-AMF-inoculated fruits had significantly higher equatorial diameter and fruit peel weight compared to FM inoculation alone. Root AM colonization was significantly and positively correlated with these internal and external quality parameters of fruits (Table 1).

Table 1. Effects of AMF inoculation on internal and external quality of fruits and Pearson's correlations between root AM colonization and fruit quality.

\begin{tabular}{|c|c|c|c|c|c|c|c|}
\hline Treatments & $\begin{array}{c}\text { Polar } \\
\text { Diameter } \\
(\mathrm{mm})\end{array}$ & $\begin{array}{c}\text { Equatorial } \\
\text { Diameter } \\
(\mathrm{mm})\end{array}$ & $\begin{array}{c}\text { Single } \\
\text { Fruit Weight } \\
\text { (g) }\end{array}$ & $\begin{array}{c}\text { Coloration } \\
\text { Value }\end{array}$ & $\begin{array}{l}\text { Fruit Peel } \\
\text { Weight } \\
\text { (g) }\end{array}$ & $\begin{array}{c}\text { Sarcocarp } \\
\text { Weight } \\
\text { (g) }\end{array}$ & $\begin{array}{c}\text { Soluble } \\
\text { Solids } \\
\text { Content }(\%)\end{array}$ \\
\hline Non-AMF & $32.0 \pm 0.8 \mathrm{~b}$ & $41.6 \pm 1.2 c$ & $33.2 \pm 2.5 b$ & $72.4 \pm 1.3 b$ & $7.3 \pm 0.4 c$ & $24.7 \pm 2.1 b$ & $11.5 \pm 0.8 b$ \\
\hline $\mathrm{FM}$ & $36.5 \pm 0.6 \mathrm{a}$ & $47.1 \pm 1.1 \mathrm{~b}$ & $43.9 \pm 2.7 \mathrm{a}$ & $74.4 \pm 1.7 \mathrm{a}$ & $11.4 \pm 0.9 \mathrm{~b}$ & $33.8 \pm 1.6 \mathrm{a}$ & $12.6 \pm 0.8 \mathrm{a}$ \\
\hline Mixed-AMF & $36.5 \pm 1.2 \mathrm{a}$ & $49.2 \pm 1.2 \mathrm{a}$ & $46.1 \pm 2.0 \mathrm{a}$ & $75.8 \pm 0.9 \mathrm{a}$ & $12.4 \pm 0.5 \mathrm{a}$ & $35.3 \pm 2.5 \mathrm{a}$ & $13.2 \pm 0.7 \mathrm{a}$ \\
\hline $\begin{array}{c}\text { Correlation } \\
\text { Root AM } \\
\text { colonization }\end{array}$ & $0.65^{* *}$ & $0.66^{* *}$ & $0.62 * *$ & 0.67 ** & 0.59 * & $0.71^{* *}$ & 0.54 * \\
\hline
\end{tabular}

Means $\pm \mathrm{SD}(n=5)$ followed by different letters indicate significant differences $(p<0.05)$ among treatments. ${ }^{*} p<0.05 ;{ }^{* *} p<0.01$. The correlation data were collected in 2019, the second year after AMF inoculation. 


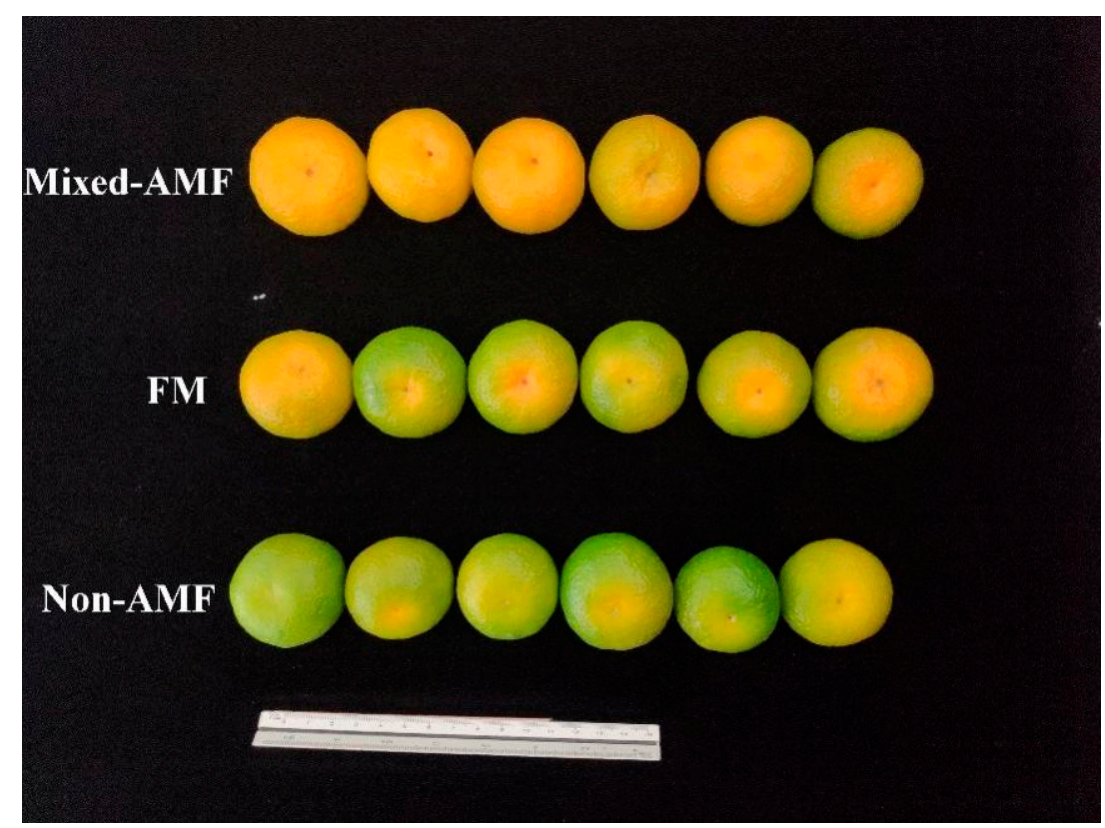

Figure 4. Changes in the appearance of fruits of Ponkan mandarin inoculated with Funneliformis mosseae (FM) and mixed-AMF, compared to uninoculated variety (non-AMF). The data were collected in 2019, the second year after AMF inoculation.

\section{Discussion}

The results of this study showed that inoculation of field-grown Ponkan mandarin with F. mosseae and mixed-AMF could significantly increase the root mycorrhizal colonization, soil hyphal length, and root vitality, indicating that the current inoculation method of AM fungi was successful in improving the status of citrus mycorrhizas under field conditions. The effects of mixed-AMF on fruit quality, root mycorrhizal colonization, and soil hyphal length were better than that of single FM inoculation, which may be due to a higher number of spores and AM-colonized root segments in mixed-AMF inocula versus FM inocula. Regvar et al. [16] inoculated pepper and tomato with AM fungi in the field and found a promoted effect on root mycorrhizal formation. It meant that although indigenous AM fungi existed in the field, the number of AM fungal spores was rather low and could not meet the requirements of plant roots to establish significant mycorrhizal symbiosis. Field inoculation with exotic AM fungi effectively promoted mycorrhizal formation and development in roots and soils in citrus. However, AM fungi are aerobic and determine the spatial distribution of AM fungal development for plants growing in field conditions [25]. The incompatibility of exogenous AMF inoculations with citrus roots in the field may be related to the selectivity between AMF and host species. Therefore, further study needs to screen an effective strain or a combination of AM fungi before being used in the field. We also need to analyze the temporal and spatial effects of field AM fungi inoculation on the development of root mycorrhiza of citrus trees and to evaluate the changes induced by exotic and indigenous AM fungal populations in the rhizosphere of field citrus.

Glomalin-related soil proteins (GRSP) are released into the soil by mycelia and spores of AM fungi [26]. It has been shown that EE-GRSP is readily produced by AM fungi as a stable and effective substance that helps to improve soil aggregate stability, soil moistureholding capacity, and plant growth, while DE-GRSP is the turnover product of EE-GRSP and might contain toxic substances [27]. The colonization of AM fungi was negatively correlated with DE-GRSP content [28]. Our results showed that both FM and mixedAMF inoculation significantly increased the content of EE-GRSP but decreased the content of DE-GRSP. This finding indicates that exotic AM fungi inoculation had the ability to improve soil structure by the increase in EE-GRSP effectively, but not DE-GRSP and to reduce growth inhibition of plants by DE-GRSP. In addition, GRSP also might contribute to 
soil nutrient cycling [6,7], but whether the nutrient contribution of GRSP is related to the improved fruit quality of citrus remains to be further studied.

Studies have shown that the degree of mycorrhizal colonization was positively correlated with plant growth responses [29]. In our study, FM and mixed-AMF inoculation significantly improved fruit size, fruit weight, coloration value, and soluble solid content, whilst soluble solid content was positively correlated with root mycorrhizal colonization. Arbuscular mycorrhizas could enhance the absorption of mineral nutrients and water by citrus roots [1] and promote the synthesis of chlorophyll and photosynthetic intensity [30], thus, accelerating fruit sugar accumulation.

In our study, the field inoculation of AM fungi into the rhizosphere of citrus had certainly promoted fruit quality and mycorrhizal formation, especially the mixed-AMF showed better advantage than single FM inoculation. Crossay et al. [31] found that coinoculation of AM fungi from different families improved plant biomass, mineral nutrition, and stress tolerance better than single AM fungal inoculation. Also, Husna et al. [32] reported that mixed-AMF inoculation was more effective on plant growth and nutrient acquisition of Kalappia celebica than a single inoculation. In addition, Singh et al. [33] found that inoculation of mixed AMF increased total phenols and total chlorophyll contents of Punica granatum more effectively than an inoculation of a single AMF. Mycorrhizal colonization and soil hyphal length were improved to a higher extent under mixed-AMF treatment compared to a single FM treatment, indicating that mixed-AMF species had a synergistic effect promoting root colonization by each other. However, the relevant interaction mechanism needs to be studied in further detail.

\section{Conclusions}

The results of this study strongly confirmed that field inoculation with exotic AM fungi, especially mixed-AMF, promoted fruit quality and the root physiological activity of citrus. Therefore, our study provides strong support for applying exotic AM fungi in field cultures of citrus and confers a new path for quality-increasing in citrus fruits. However, this study analyzed the effects of AM fungi on fruit quality and root physiological activity of citrus only in the second year after inoculation, and the tested trees were just four years old at the time of analysis. A long-term evaluation of field inoculations with AM fungi on citrus fruit quality and tree growth is needed, for supporting success of field inoculations and to evaluate the benefits of mycorrhizae applications in field citrus cultures.

Author Contributions: Conceptualization, Q.-S.W.; methodology, M.-A.C. and P.W.; data determination and statistical analysis, M.-A.C. and P.W.; writing-original draft preparation, M.-A.C., P.W. and Q.-S.W.; writing—review and editing, A.H., S.W., E.F.A. and Q.-S.W.; supervision, Q.-S.W. All authors have read and agreed to the published version of the manuscript.

Funding: This research was funded by the Hubei Agricultural Science and Technology Innovation Action Project (Hubei Nongfa [2018] No. 1) and the Natural Science Foundation of Zhejiang Province (LY19C150001). The authors would like to extend their sincere appreciation to the Researchers Supporting Project Number (RSP-2021/356), King Saud University, Riyadh, Saudi Arabia.

Institutional Review Board Statement: Not applicable.

Informed Consent Statement: Not applicable.

Data Availability Statement: All the data supporting the findings of this study are included in this article.

Acknowledgments: This work was supported by the Hubei Agricultural Science and Technology Innovation Action Project (Hubei Nongfa [2018] No. 1) and the Natural Science Foundation of Zhejiang Province (LY19C150001). The authors would like to extend their sincere appreciation to the Researchers Supporting Project Number (RSP-2021/356), King Saud University, Riyadh, Saudi Arabia.

Conflicts of Interest: The authors declare no conflict of interest. 


\section{References}

1. Zou, Y.N.; Wu, Q.S.; Kuča, K. Unravelling the role of arbuscular mycorrhizal fungi in mitigating the oxidative burst of plants under drought stress. Plant Biol 2021, 23 (Suppl. 1), 50-57. [CrossRef]

2. Agnolucci, M.; Avio, L.; Pepe, A.; Turrini, A.; Cristani, C.; Bonini, P.; Cirino, V.; Colosimo, F.; Ruzzi, M.; Giovannetti, M. Bacteria associated with a commercial mycorrhizal inoculum: Community composition and multifunctional activity as assessed by Illumina sequencing and culture-dependent tools. Front. Plant Sci. 2019, 9, 1956. [CrossRef]

3. Wright, S.F.; Franke-Snyder, M.; Morton, J.B.; Morton, A.; Upadhyaya, A. Time-course study and partial characterization of a protein on hyphae of arbuscular mycorrhizal fungi during active colonization of roots. Plant Soil 1996, 181, 193-203. [CrossRef]

4. He, S.B.; Long, M.X.; He, X.Q.; Guo, L.X.; Yang, J.Y.; Yang, P.Z.; Hu, T.M. Arbuscular mycorrhizal fungi and water availability affect biomass and C: N: P ecological stoichiometry in alfalfa (Medicago sativa L.) during regrowth. Acta Physiol. Plant. 2017, 39, 199-208. [CrossRef]

5. Wright, S.F.; Upadhyaya, A. A survey of soils for aggregate stability and glomalin a glycoprotein of arbuscular mycorrhizal fungi. Plant Soil 1998, 198, 97-107. [CrossRef]

6. He, J.D.; Chi, G.G.; Zou, Y.N.; Shu, B.; Wu, Q.S.; Srivastava, A.K.; Kuča, K. Contribution of glomalin-related soil proteins to soil organic carbon in trifoliate orange. Appl. Soil Ecol. 2020, 154, 103592. [CrossRef]

7. Meng, L.L.; He, J.D.; Zou, Y.N.; Wu, Q.S.; Kuča, K. Mycorrhiza-released glomalin-related soil protein fractions contribute to soil total nitrogen in trifoliate orange. Plant Soil Environ. 2020, 66, 183-189. [CrossRef]

8. Ali, A.; Ghani, M.I.; Ding, H.Y.; Fan, Y.; Cheng, Z.H.; Iqbal, M. Co-amended synergistic interactions between arbuscular mycorrhizal fungi and the organic substrate-induced cucumber yield and fruit quality associated with the regulation of the AM-fungal community structure under anthropogenic cultivated soil. Int. J. Mol. Sci. 2019, 20, 1539. [CrossRef]

9. Wu, Q.S.; Zou, Y.N.; Liu, C.Y.; Lu, T. Interacted effect of arbuscular mycorrhizal fungi and polyamines on root system architecture of citrus seedlings. J. Integr. Agric. 2012, 11, 1675-1681. [CrossRef]

10. Song, F.; Bai, F.X.; Wang, J.J.; Wu, L.M.; Jiang, Y.C.; Pan, Z.Y. Influence of citrus scion/rootstock genotypes on arbuscular mycorrhizal community composition under controlled environment condition. Plants 2020, 9, 901. [CrossRef] [PubMed]

11. Wang, P.; Wang, T.Y.; Wu, S.H.; Weng, M.X.; Lu, L.M.; Ke, F.Z.; Wu, Q.S. Effect of arbuscular mycorrhizal fungi on rhizosphere organic acid content and microbial activity of trifoliate orange under different low P conditions. Arch. Agron. Soil Sci. 2019, 65, 2029-2042. [CrossRef]

12. Liang, S.M.; Zhang, F.; Zou, Y.N.; Kucča, K.; Wu, Q.S. Metabolomics analysis reveals drought responses of trifoliate orange by arbuscular mycorrhizal fungi with a focus on terpenoid profile. Front. Plant Sci. 2021, 12, 740524. [CrossRef]

13. Cheng, H.Q.; Zou, Y.N.; Wu, Q.S.; Kuča, K. Arbuscular mycorrhizal fungi alleviate drought stress in trifoliate orange by regulating $\mathrm{H}^{+}$-ATPase activity and gene expression. Front. Plant Sci. 2021, 12, 659694. [CrossRef] [PubMed]

14. Sabra, M.; Aboulnasr, A.; Franken, P.; Perreca, E.; Wright, L.P.; Camehl, I. Beneficial root endophytic fungi increase growth and quality parameters of sweet basil in heavy metal contaminated soil. Front. Plant Sci. 2018, 27, 1726. [CrossRef]

15. Lin, A.J.; Zhang, X.H.; Wong, M.H.; Ye, Z.H.; Lou, L.Q.; Wang, Y.S.; Zhu, Y.G. Increase of multi-metal tolerance of three leguminous plants by arbuscular mycorrhizal fungi colonization. Environ. Geochem. Health 2007, 29, 473-481. [CrossRef]

16. Regvar, M.; Vogel-Miku, K.; Everkar, T. Effect of AMF inoculum from field isolates on the yield of green pepper, parsley, carrot, and tomato. Folia Geobot. 2003, 38, 223-234. [CrossRef]

17. Ercol, L.; Arthur, S.; Iduna, A.; Elisa, P. Strong increase of durum wheat iron and zinc content by field-inoculation with arbuscular mycorrhizal fungi at different soil nitrogen availabilities. Plant Soil 2017, 419, 153-167. [CrossRef]

18. Marie-Stéphanie Kouadio, A.N.; Nandjui, J.; Krou, S.M.; Jean-Marc Séry, D.; Nelson, P.N.; Adolphe, Z. A native arbuscular mycorrhizal fungus inoculant outcompetes an exotic commercial species under two contrasting yam field conditions. Rhizosphere 2017, 4, 112-118. [CrossRef]

19. Paskovic, I.; Soldo, B.; Ban, S.G.; Radic, T.; Lukic, M.; Urlic, B.; Mimica, M.; Bubola, K.B.; Colla, G.; Rouphael, Y.; et al. Fruit quality and volatile compound composition of processing tomato as affected by fertilisation practices and arbuscular mycorrhizal fungi application. Food Chem. 2021, 359, 129961. [CrossRef]

20. Ortas, I. Mycorrhiza in citrus: Growth and nutrition. In Advances in Citrus Nutrition; Srivastava, A.K., Ed.; Springer: New York, NY, USA, 2012; pp. 333-352.

21. Phillips, J.M. Improved procedures for clearing roots and staining parasitic and vesicular-arbuscular mycorrhizal fungi for rapid assessment of infection. Trans. Br. Mycol. Soc. 1970, 55, 158-161. [CrossRef]

22. Bethlenfalvay, G.J.; Ames, R.N. Comparison of two methods for quantifying extraradical mycelium of vesicular-arbuscular mycorrhizal fungi. Soil Sci. Soc. Am. J. 1987, 51, 834-837. [CrossRef]

23. Lindström, A.; Nyström, C. Seasonal variation in root hardiness of container-grown Scots pine, Norway spruce, and lodgepole pine seedlings. Can. J. For. Res. 1987, 17, 787-793. [CrossRef]

24. Wu, Q.S.; Cao, M.Q.; Zou, Y.N.; He, X.H. Direct and indirect effects of glomalin, mycorrhizal hyphae, and roots on aggregate stability in rhizosphere of trifoliate orange. Sci. Rep. 2014, 4, 5823. [CrossRef] [PubMed]

25. Valverde-Barrantes, O.J.; Smemo, K.A.; Feinstein, L.M.; Kershner, M.W.; Blackwood, C.B. Patterns in spatial distribution and root trait syndromes for ecto and arbuscular mycorrhizal temperate trees in a mixed broadleaf forest. Oecologia 2018, 186, 731-741. [CrossRef] 
26. Lovelock, C.E.; Wright, S.F.; Ruess, C. Soil stocks of glomalin produced by arbuscular mycorrhizal fungi across a tropical rain forest landscape. J. Ecol. 2004, 92, 278-287. [CrossRef]

27. Liu, R.C.; Gao, W.Q.; Srivastava, A.K.; Zou, Y.N.; Kuča, K.; Hashem, A.; Abd_Allah, E.F.; Wu, Q.S. Differential effects of exogenous glomalin-related soil proteins on plant growth of trifoliate orange through regulating auxin changes. Front. Plant Sci. 2021, 12, 745402. [CrossRef]

28. Wu, Q.S.; Li, Y.; Zou, Y.N.; He, X.H. Arbuscular mycorrhiza mediates glomalin-related soil protein production and soil enzyme activities in the rhizosphere of trifoliate orange grown under different P levels. Mycorrhiza 2015, 25, 121-130. [CrossRef]

29. Tchiechoua, Y.H.; Kinyua, J.; Ngumi, V.W.; Odee, D.W. Effect of indigenous and introduced arbuscular mycorrhizal fungi on growth and phytochemical content of vegetatively propagated Prunus africana (Hook. f.) Kalkman provenances. Plants 2020, 9, 37. [CrossRef]

30. Shabani, E.; Bolandnazar, S.; Tabatabaei, S.J. Magnetized phosphorus solution and mycorrhization with Diversispora versiformis affect $P$ use efficiency, growth and photosynthetic parameters in sweet basil (Ocimum basilicum). Hortic. Res. 2019, 27, 103-112. [CrossRef]

31. Crossay, T.; Majorel, C.; Redecker, D.; Gensous, S.; Amir, H. Is a mixture of arbuscular mycorrhizal fungi better for plant growth than single-species inoculants? Mycorrhiza 2019, 29, 325-339. [CrossRef]

32. Tuheteru, F.D.; Arif, A. The potential of arbuscular mycorrhizal fungi to conserve Kalappia celebica, an endangered endemic legume on gold mine tailings in Sulawesi, Indonesia. J. For. Res. 2021, 32, 675-682.

33. Singh, N.V.; Singh, S.K.; Singh, A.K.; Meshram, D.T.; Suroshe, S.S.; Mishra, D.C. Arbuscular mycorrhizal fungi (AMF) induced hardening of micropropagated pomegranate (punica granatum L.) plantlets. Sci. Hortic. 2012, 136, 122-127. [CrossRef] 